\title{
Impact of Using History of Mathematics on Students' Mathematics Attitude: A Meta-Analysis Study
}

\author{
Suphi Önder Bütüner ${ }^{1}$ \\ ${ }^{1}$ Assist. Prof. Dr, Department of Elementary Mathematics Education, Bozok University, Yozgat, Turkey \\ For correspondence: s.onder.butuner@bozok.edu.tr, onderbutuner@mynet.com
}

\begin{abstract}
The main objective of hereby study is to unearth the big picture, reaching studies about influence of using history of mathematics on attitude of mathematics among students. 6 studies with a total effect size of 14 that comply with coding protocol and comprise statistical values necessary for meta-analysis are combined via meta-analysis method among 53 studies on history of mathematics since 2000. The validity of the study is determined by means of funnel plot, Orwin's FSN and Egger's regression tests, while the reliability of coding protocol is identified through calculation of Cohen Kappa inter-coder agreement value. The model to be used in the analysis is decided with the help of homogeneity test, $\mathrm{Q}$ and $\mathrm{I}^{2}$ statistic. In analyses, the Cohen d effect size of each comparative study is calculated. At the end of the study, it is found that no publication bias exists since Orwin's FSN is calculated as 119 and the Funnel plot, pursuant to Egger's regression test, has a symmetric structure. The inter-coder reliability is detected as 1.00 . As the value $\mathrm{I}^{2}$ displays low level heterogeneity with $16.622 \%$, fixed effect model is used for analysis. Average effect size is found $d=0.095$ (lower limit and upper limit of confidence interval at $95 \%$ are -0.693 and 0.951 , respectively) in favor of experimental group, as positive and at negligible level.
\end{abstract}

Keywords: attitude, history of mathematics, meta-analysis, fixed effect model

\section{Introduction}

For many years, the usage of history of mathematics (HoM) in mathematics teaching has been encouraged (Barwell, 1913; Groza, 1968). In the last ten years, the studies regarding usage of HoM in learning environment gradually increased (Jankvist, 2009b). As for Turkey, the history of mathematics got into textbooks in 2005 together with the new primary education mathematics curriculum. The general objectives within primary education mathematics program lay stress on the necessity of benefiting from HoM.

Many researchers agree that the usage of HoM in learning environments will help students in adopting a positive attitude towards mathematics and contribute to their learning (Barwell, 1913; Groza, 1968; Arcavi, 1991; Fauvel, 1991; Bidwell, 1993; Ernest, 1998; Wilson and Chauvot, 2000; Fried, 2001; Gulikers and Blom, 2001; Tzanakis and Arcavi, 2002; Liu, 2003; Baki, 2008; Jankvist, 2009a, $2009 \mathrm{~b}, 2010$ ). As a matter of fact, the studies reveal that the usage of HoM changes the attitude of students towards mathematics (McBride and Rollins, 1977; Ponza, 1998; Lim, 2011), increases their successes (Awosanya, 2001; Leng, 2006; Glaubitz, 2007; Nataraj and Thomas, 2009; Bellomo and Wertheimer, 2010), and deepens their beliefs in the nature of mathematics (Percival, 1999; Krussel, 2000; Liu and Niess, 2006; Kaye, 2008).

In the face of such positive opinions on using history of mathematics, there are also studies that assert and manifest certain obstacles in this process (Fried, 2001; Tzanakis and Arcavi, 2002; Gönülateş, 2004; Siu, 2007; Ho, 2008; Horton, 2011; Panasuk and Horton, 2012). Fried (2001) claims history of mathematics can be used via strategies of addition and adaptation, but usage of such strategies may 
lead to contradictions. In strategy of addition, the historical anecdotes, short biographies, and problems are incorporated within curriculum. Fried expresses that the adding strategy will cause shortage of time due to intense curriculum, which in turn will lead to unsuccessful practice. As for adaptation strategy, the school curricula should be configured on the basis of historical developments and events. Fried claims this strategy will be unsuccessful and degrade the history because of reading texts with distorted historical content and regulations to reduce historical value.

Tzanakis and Arcavi (2002) gather the obstacles to the usage of HoM under two categories, namely, obstacles in philosophical aspect and in application process. They treat philosophical obstacles under the titles of "History is not mathematics," "History may lead to confusion rather than setting light to mathematical concepts," "Most students do not like history so they will not like HoM either," "The objective of mathematics course is to ensure that students solve hard, routine problems. Then there is no need to use history," and "Usage of history is likely to pave way for cultural chauvinism." They summed up the practical obstacles under the titles of "shortage of time," "shortage of sources," "lack of knowledge and experience on how to assess students," and "lack of knowledge and experience among teachers regarding how they can benefit from HoM."

Teacher candidates who participated in the thesis study of Gönülateş (2004) lay stress on potential obstacles to the usage of HoM, indicating that due to lack of sufficient time, in case the material exercises do not comply with the level of students, they may lead to confusion and accordingly students may suffer a dilemma between mathematics and history. Siu (2007) expresses 16 obstacles regarding the usage of history of mathematics. Ho (2008) finds out that according to data from 1000 teachers, more than $90 \%$ of them do not apply HoM in classes. The most common obstacle is the lack of knowledge among teachers in using historical content (16.9\%). In his study, Horton (2011) asks 367 teachers to declare whether they allow for HoM in the lessons, as well as their primary reasons. In response, 133 teachers state they do not employ any content regarding HoM in the lesson. Teachers ground this deficiency on four reasons, namely, "shortage of time," "multiple-choice exams students will take," "shortage of sources," and "lack of knowledge, skill, and experience regarding usage of HoM." Panasuk and Horton (2012) search whether and why mathematics teachers employ HoM in the lessons. Teachers who do not allow for HoM explain the primary reasons as their lack of sufficient knowledge and skill on usage of HoM, shortage of sources, shortage of time, and irrelevance of HoM to the exams students take. The presence of negative opinions as well as the positive ones concerning the usage of history of mathematics calls to mind whether its usage is effective on students' mathematics attitude.

On the other hand, Affective factors are said to play significant roles in learnerachievement in mathematics (Grootenboer \& Hemmings, 2007). One factor that is highlyassociated with pupil achievement is the pupils' attitudes towards mathematics. Each successive TIMSS assessment has shown a strong positive relationship within countries between student attitudes toward mathematics and their mathematics achievement. Additionally, there is extensive research showing that students with more positive attitudes toward mathematics has higher average achievement in mathematics. For example, a recent meta-analysis of student attitudes toward school found that attitudes toward mathematics or science were related to mathematics and science achievement across 288 studies (Hattie, 2009; as cited in Mullis et al, 2012).Kusum Singh, Monique Granville, and Sandra Dika (2002) conducted a studycomparing the effect of attitude and other variables on academicperformance among eighth graders in the areas of mathematics.The study of the total effects revealed the important influences of attitude on achievement. Of primary importance is the evidenceof the strong effects of motivation, positive attitude, and engagement in academic work for success in mathematics (Singh, Granville, \& Dika, 2002; as cited in Michelli, 2013). 
Therefore we need a meta-analytic impact analysis pursuant to researches in Turkey and abroad in order to reveal in a wide scale the influence of using history of mathematics on attitude. The objective of meta-analysis is to combine the results obtained via small-scale individual studies in various places and times in order to put forth the facts. Thus, the number of samples will rise and various studies will enable attaining the quantitative truth (Y1ldiz, 2002). For this purpose, the main objective of hereby study is to unearth the big picture, reaching studies about influence of using history of mathematics on attitude of mathematics among students.

\section{Method}

\section{Research Model}

In relevant literature, there is no consensus about the exact significance of the term "meta-analysis." Upon the study by Smith and Glass (1977), the meaning of meta-analysis became clear and understood as follows: "meta-analysis is more than a statistical technique; (meta-analysis) is a method used for systematic analysis of a group of researches (Üstün and Eryılmaz, 2014). Our study employs meta-analysis, which is a systematic synthesis method. In a meta-analysis, the findings from studies carried out in different places and times are combined; thus number of samples is enhanced so as to attain most accurate quantitative conclusion (Ellis, 2012).

\section{Data Acquisition}

The main data source of hereby study is the doctorate and postgraduate theses, articles and papers about history of mathematics in Turkey and abroad. "YOK national thesis center," "Proquest dissertation" database of Karadeniz Technical University, and "Google Scholar" are used in order to have access to theses in Turkey and abroad. For articles, we searched "databases subscribed by Karadeniz Technical University," "Google Scholar," and "Ulakbilim," while for papers, we scanned "published paper booklets" and "Google Scholar." In the searches, we used keywords "history of mathematics," "ancient," "attitude" "mathematics," "student," and "history." In the end, 53 applied studies, conducted between years 2000 and 2014, were found. Among them, we removed those that cannot procure necessary criteria. Among the 53 studies, 47 are not included in our analysis. The criteria for inclusion and exclusion are explained below.

\section{Inclusion and Exclusion Criteria}

The criteria in selection of studies included by hereby research are as follows: "studies published between years 2000 and 2014", "postgraduate and doctorate (PhD) theses, reviewed and nonreviewed academic journals, papers presented at congresses and symposiums", "the studies should be of experimental nature so that we can attain standardized effect size via meta-analysis studies", "incorporation of sufficient numerical data such as $\mathrm{p}$ value, $\mathrm{t}$ value, $\mathrm{F}$ value, number of samples, standard deviation, and average for calculating the effect size of studies". Studies, which do not concentrate on the impact of using history of mathematics on attitude or do not include sufficient statistical data for meta-analysis, are excluded. All 53 studies are given below, together with their respective study groups, methods, and dependent variables.

Table 1. Overview of studies on history of mathematics

\begin{tabular}{llll}
\hline \multicolumn{1}{c}{ Author-Year } & Study Group & Method & Decision \\
\hline Sullivan (2000) & Teac. Cand & Quantitative & Excluded \\
Miller (2002) & Teac. cand & Qualitative & Excluded \\
Gönülgüneş (2004) & Teac. cand & Quantitative & Excluded \\
Percival (2004) & Math. teac & Qualitative & Excluded \\
Furinghetti (2007) & Teac. cand & Qualitative & Excluded \\
Goodwin (2007) & Teac & Quantitative & Excluded \\
Siu (2007) & Math. teac & Quantitative & Excluded \\
\hline
\end{tabular}




\begin{tabular}{|c|c|c|c|}
\hline Smestad (2008) & Teac & Qualitative & Excluded \\
\hline Baki; Güven (2009) & Teac. cand & Unspecified & Excluded \\
\hline Charalambous et al. (2009) & Teac. cand & Quantitative & Excluded \\
\hline Ho (2008) & Math teac & Quantitative & Excluded \\
\hline Burns (2010) & Teac. cand & Mixed & Excluded \\
\hline Gürsoy (2010) & Teac. cand & Quantitative & Excluded \\
\hline Huntley; Flores (2010) & Teac. cand & Qualitative & Excluded \\
\hline Horton (2011) & Teac & Quantitative & Excluded \\
\hline Horton; Panasuk (2011) & Math. teac & Quantitative & Excluded \\
\hline Yenilmez (2011) & Teac. cand & Quantitative & Excluded \\
\hline Clark (2012) & Teac. cand & Qualitative & Excluded \\
\hline Gazit (2012) & Teac-Teac cand & Quantitative & Excluded \\
\hline Panasuk, Horton (2012) & Math. teac & Quantitative & Excluded \\
\hline Aydoğdu ve Yüksel (2013) & Teac. cand & Quantitative & Excluded \\
\hline Yildız (2013) & Math. teac & Unspecified & Excluded \\
\hline Alpaslan et al. (2014) & Math teac & Quantitative & Excluded \\
\hline Fenaroli et al. (2014) & Teac cand & Qualitative & Excluded \\
\hline Marshall (2000) & Sec. Sch. student & Quantitative & Included \\
\hline Dickey (2001) & Ele. Sch. student & Qualitative & Excluded \\
\hline Lit vd. (2001) & Ele. Sch. student & Quantitative & Included \\
\hline Lawrence (2006) & Sec. Ele. Sch. stud & Qualitative & Excluded \\
\hline Leng (2006) & Ele. Sch. student & Quantitative & Excluded \\
\hline Glaubitz (2007) & Sec. Sch. student & Quantitative & Excluded \\
\hline İdikut (2007) & Ele. Sch. student & Quantitative & Included \\
\hline Yevdokimov (2007) & Sec. Sch. student & Qualitative & Excluded \\
\hline Haile (2008) & Ele. Sch. student & Qualitative & Excluded \\
\hline Kaye (2008) & Ele. Sch. student & Qualitative & Excluded \\
\hline Tözluyurt (2008) & Sec. Sch. student & Qualitative & Excluded \\
\hline Liu (2009) & Sec. Sch. student & Qualitative & Excluded \\
\hline Nataraj; Thomas (2009) & Ele. Sch. student & Quantitative & Excluded \\
\hline Belloma;Wertheimer (2010) & Sec. Sch. student & Quantitative & Excluded \\
\hline Karaduman (2010) & Ele. Sch. student & Quantitative & Excluded \\
\hline Albayrak (2011) & Ele. Sch. student & Quantitative & Excluded \\
\hline Kaygin et al. (2011) & Ele. Sch. student & Quantitative & Excluded \\
\hline $\operatorname{Lim}(2011)$ & University & Quantitative & Included \\
\hline Bayam (2012) & Ele. Sch. student & Quantitative & Included \\
\hline Özdemir et al. (2012) & Sec. Sch. student & Qualitative & Excluded \\
\hline Bütüner (2014) & Ele. Sch. student & Qualitative & Included \\
\hline Krussel (2000) & Undgra. student & Qualitative & Excluded \\
\hline Awosanya (2001) & Undgra. student & Quantitative & Excluded \\
\hline Mayfield (2001) & Undgra. student & Qualitative & Excluded \\
\hline Liu,Niess (2006) & Undgra. student & Qualitative & Excluded \\
\hline Haverhals,Roscoe (2010) & Undgra. student & Qualitative & Excluded \\
\hline Jankvist (2010) & Undgra. student & Qualitative & Excluded \\
\hline Başıbüyük (2012) & Undgra. student & Quantitative & Excluded \\
\hline Povey (2014) & Faculty member & Qualitative & Excluded \\
\hline
\end{tabular}

Table 1 reveals that among 53 applied study groups, 47 are not included within analysis since they are not compliant in terms of method or lack sufficient statistical data. Among 47 studies, two (Ho, 2008; Haverhals and Roscoe, 2010) are excluded because they do not report statistical data for calculating effect size. Three studies (Dittrich, 1973; McBride and Rollins, 1977; Ponza, 1998) are 
excluded because of publication date. Therefore, 6 studies, with a total reported effect size of 14, are included within meta-analysis. In terms of number of effect sizes, in relevant literature Preston (2007) uses 18 effect sizes in his PhD study, Özcan (2008), Özcan and Bakioğlu (2010), and Aloe, Amo and Shanahan (2013) use 16, Şen and Yılmaz (2013) and Aydın, Sarıer and Uysal (2011) use 15, while Tavil and Karasu (2013) use 6 effect size from 8 studies in order to conduct their respective meta-analyses. Details about the included studies are briefly given in Table 2 .

Table 2. Included studies

\begin{tabular}{lcclll}
\hline Author & Study Sample Size & Year & Publication Type & School Level & Country \\
& & & & & \\
\hline Marshall & 32 & 2000 & Thesis & High & Abroad \\
İdikut & 85 & 2007 & Thesis & Elementary & Turkey \\
Bayam & 44 & 2008 & Thesis & Elementary & Turkey \\
Lim & 103 & 2011 & Paper & University & Abroad \\
Lit et al. & 76 & 2001 & Article & Elementary & Abroad \\
Bütüner & 24 & 2014 & Thesis & Elementary & Turkey \\
\hline
\end{tabular}

As seen in Table 2, all 6 included studies are conducted as of 2000, 3 of them are carried out in Turkey and the remaining 3 are carried out abroad. Total number of samples in 11 studies is 364.4 studies focus on elementary education; while 1 concentrates on university level. 4 of these studies are thesis, followed by 2 articles.

\section{Model Selection in Meta-Analysis}

Two models are used in meta-analysis. The first is fixed effect model, while the second one is random effect model (Shelby and Vaske, 2008). In fixed effect model, it is assumed that all studies included within meta-analysis have a general common effect size. Pursuant to this assumption, the differences in observed effects are exclusively due to sampling errors (Hunter and Schmidt, 2004; Rosenthal, Hoyt, Ferrin, Miller and Cohen, 2006). In random effect model, the correct effect size varies depending on study. The differentiation of effect sizes in random effect model is due to independent variables that are considered to have effect on dependent variable (attitude). In meta-analysis, independent variables are expressed as study moderators. Study moderators are independent variables that are thought to be influential on study outputs and are sued in meta-analysis in order to determine the size of this impact (Üstün, 2012; Kış, 2013). Publication type, place of study, and application level is stipulated as study moderators. It is decided on whether the analysis will be conducted using fixed effect or random effect model pursuant to heterogeneity test, and $\mathrm{Q}$ and $I^{2}$ statistics (Higgins et al, 2003).

\section{Coding Method, Coding Reliability}

A proper coding protocol is essential for flawless conduct of meta-analysis. Coding protocol consists of two parts. The coding of independent variables, which are thought to be influential on study outputs, namely, study moderators (publication type, school level, country), is carried out in the first part. As for the second, the statistical values (standard deviation, average, $t$ value, $p$ value, number of samples), which are necessary for calculating effect size and are reported in studies, are coded (Lipsey and Wilson, 2001). The reliability of coding protocol should be statistically ensured. For this purpose, Cohen's Kappa test is conducted in meta-analysis in order to evaluate the level of agreement between coders (Card, 2012).

In hereby study, the coding protocol comprises three parts. The first part is the identity of study. "Author(s)", "year of research" are coded in this section. The second part is study content, and includes the coding of independent variables "publication type", "school level", and "country". As 
for third part, the coding of statistical values, which are reported in studies, takes place. Coding protocol is coded by researcher (coder 1) and a specialist academician (coder 2). According to certain sources (Card, 2012), Cohen's Kappa statistic may yield a more reliable result thanks to frequency data between coders, in consideration of chance due to rareness of options in mentioned agreement level. Results of Cohen's Kappa test are given in Table 3. According to Table 3, inter-coder reliability is 1.00. This result signifies a perfect agreement between coders (Viera and Garrett, 2005).

Table 3.Results of kappa test on agreement between coders

\begin{tabular}{lcccc}
\hline & \multicolumn{4}{c}{ Coder 1 } \\
\hline Coder 1 & 1 & 2 & Total \\
& 1 & 29 & 0 & 29 \\
\multirow{2}{*}{ Total } & 0 & 7 & 7 \\
& & 29 & 7 & 36 \\
\multicolumn{2}{l}{ Measure of Agreement Kappa } & 1.00 & Asymp. Std. & Approx. Sig. \\
\hline
\end{tabular}

\section{Validity of Study}

A research on the presence of publication bias within the studies in meta-analysis, as well as on the quality of included sources, may reveal whether the validity of meta-analysis studies is ensured. Studies that report high effect size and significant results are more likely to be published than those with low effect size and without significant results. Meta-analysis most probably comprises published studies; therefore, certain biases in the literature are reflected in meta-analysis as well. This fact is known as publication bias (Banks, Kepes and Banks, 2012; Üstün, 2012; Kış, 2013). Other bias types that may have an impact on meta-analysis results include language bias (usage of mostly English database and magazines in studies, ignorance of magazines published in other languages), presence bias (selection of easy access by researchers as an inclusion criterion), and cost bias (preference of free or cheaper database and magazines during selection) (Borenstein et al, 2009). In hereby study, publication bias is tested via three methods, namely, (a) Funnel Plot (b) Orwin's FSN and (c) Egger's regression test (Üstün, 2012).

Information regarding the combined effect size in meta-analysis becomes valid to the extent of validity of studies included in analysis (Petitti, 2000). In case data collection tools in all studies within the analysis are valid, this will ensure validity of meta-analysis as well. It is found that all 6 studies, included within meta-analysis, ensure validity of data collection tools.

\section{Data Analysis}

In the analyses, effect size Cohen $\mathrm{d}=x_{d}-x_{k} / \mathrm{s}$ of each comparative study is calculated; andthesignificance level for the analysis was chosen as .05.The effect size ' $\mathrm{d}$ ' is just the standardized mean difference between the two groups (Cooper, 1989).In the formula, $x_{d}$ means the average of experimental group, $x_{k}$ is control group average, while $\mathrm{s}$ is accumulated standard deviation (Darabi, Liang, Suryavanshi and Yürekli, 2013).

Statistical Package CMA 2.0 [Comprehensive Meta-Analysis] (Borenstein et al, 2005) is used in calculating the effect sizes of studies. The obtained effect sizes are interpreted grounding on the classification by Cohen (1988). According to this classification, the value between $0.20-0.50$ signifies low level effect, $0.50-0.80$ means medium effect, whereas any figure higher than 0.80 shows high effect. The software SPSS 15.0 is employed for coder reliability test. The classification by Viera and Garrett (2005) is used for interpreting Kappa test results. Since the significance level of included studies is considered 0.05 , the significance level of statistical analyses in hereby research is also set at 0.05 . 


\section{Findings}

The problem of our study is formulated as follows: "What is the average effect size of HoM usage in learning-teaching environment on attitude of students in mathematics?" In order to answer this problem, certain analyses are carried out on relevant data from studies included in our research. In the wake of analyses, the findings on publication bias, heterogeneity test, $I^{2}$ statistics, descriptive statistics, fixed effect model, forest plot are given below.

\section{Publication Bias}

Publication bias mainly concerns about the validity of a meta-analysis study (Lipsey \& Wilson, 2001). The validity of the results of a meta-analysis study is threatened if the studies included in the metaanalysis are biased (Rothstein et al, 2005). The funnel plot was plotted with effect size on the $X$ axis and the sample size or variance on the $\mathrm{Y}$ axis. Large studies appear toward the top of the graph and generally cluster around themean effect size. Smaller studies appear toward the bottom of the graph and (since smaller studies have more sampling error variation in effect sizes) tend to be spread across a broad range of values. This pattern resembles a funnel, hence the plot's name. In the absence of publication bias, the studies will be distributed symmetrically about the mean effect size, since the sampling error is random. In the presence of publication bias the studies are expected to follow the model, with symmetry at the top, a few studies missing in the middle, and more studies missing near the bottom (Light et al., 1994, as cited in Borenstein et al, 2009; Rachel, 2007). Funnel plot is given below.

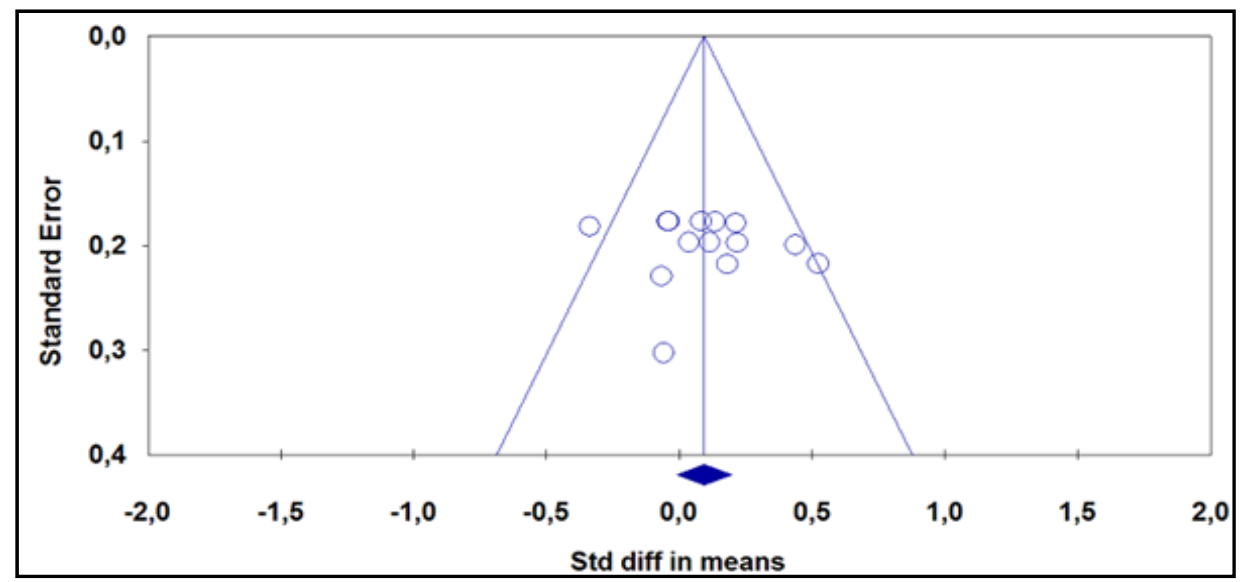

Figure 1. Funnel plot

An examination of Figure 1 shows that these studies are distributed symmetricallyon both sides of vertical line showing the effect size, so we can say there is no publication bias. Orwin's FSN and Egger's regression test are used in order to test publication bias. Orwin's FailSafe N calculates the number of studies that are likely to be excluded from the meta-analysis (Rachel, 2007; Borenstein et al, 2009).Table 4 illustrates Orwin's FSN findings for publication bias.

Table 4. Orwin's FSN findings for publication bias

\begin{tabular}{lc}
\hline Element & Value \\
\hline Std diff in means in observed studies & 0.09457 \\
Criterion for a 'trivial' Hedge's g & 0.01000 \\
Mean Hedge's g in missing studies & 0.00000 \\
Fail safe N & 119 \\
\hline
\end{tabular}

Table 4 illustrates the results of the calculations for this meta-analysis, which means that additional 119 studies with effect sizes of 0.00000 are necessary to bring the mean effect of this meta-analysis 
under 0.1 , which can be called as trivial in many contexts. The result is considered as an indicator of the non-presence of publication bias in hereby meta-analysis (Üstün, 2012; Camnalbur and Erdoğan; 2008; Kış, 2013).Funnel plots are useful visuals to getting a sense of data about publication bias. However, it does not provide a quantitative way to detect biased results. On the other hand, Egger et al. (1997) suggest a linear regression approach to test statistically whether there exist any bias in thedata included in meta-analysis (Egger et al, 1997, as cited in Üstün, 2012).Table 5 illustrates Egger's regression test findings for publication bias.

Table 5.Egger's regression test findings

\begin{tabular}{ll}
\hline Intercept & 1.15770 \\
Standard error & 2.37164 \\
$\% 95$ lower bound & -4.00965 \\
$\% 95$ upper bound & 6.32506 \\
$\mathrm{t}$ value & 0.48814 \\
$\mathrm{df}$ & 12 \\
$\mathrm{p}$ value (2 tailed) & 0.63424 \\
\hline
\end{tabular}

This result (absence of publication bias) is also supported by the results of Egger's Regression Test as summarized in Table 5 since the null hypothesis that "there is no funnel plot asymmetry" cannot be rejected $(\mathrm{p}>0.05)$.

\section{HeterogeneityTest, $Q$ and $I^{2}$ Statistics}

It was considered that the study distributionmay show some heterogeneity, so to test thisheterogeneity, $Q$ and $I^{2}$ statistics were used (Cooper et al., 2009).Q was found as 15,592. 13 degrees of freedom at a significance level of $95 \%$ from $\chi 2$ table was found to be 22,362 . The hypothesis on the absence of homogeneity in terms of the distribution of effect sizes was accepted in fixed effect model because $\mathrm{Q}$-statistics value $(\mathrm{Q}=15,592)$ doesn't exceed the critical chi square distribution value $(\chi 20,95=22,362)$ with a degree of freedom of 16 . Thus, effect sizes distribution was determined to be homogeneous in accordance with fixed effect model $(p>0,05)$.

Table 6.Results of heterogeneity test regarding effect size distribution

\begin{tabular}{cccc}
\hline $\mathrm{Q}$ value & $\mathrm{df}(\mathrm{Q})$ & $\mathrm{P}$ & $I^{2}$ \\
\hline 15.592 & 13 & 0.272 & 16.622 \\
\hline
\end{tabular}

Unlike Q statistic, $I^{2}$ statistic is not affected by the number of studies. During the interpretation of $I^{2} 25 \%$ indicates a low-level heterogeneity, 50\% indicatesa mid-level heterogeneity and $75 \%$ shows a high-level heterogeneity(Cooper et al, 2009). In Table 6, the results show a low level of heterogeneity( $\left.I^{2}=16,622\right)$.In other words, it is concluded that fixed effect model was used for analysis.

\section{Fixed Effect Model}

Effect sizes of HoM usage on mathematics attitude among students are listed from smaller to bigger effect size values; the standard error, lower, and upper limits pursuant to reliability range of $95 \%$, and significance values are given in Table 7

Table 7. Fixed effect model findings

\begin{tabular}{cccccccc}
\hline $\begin{array}{c}\text { Study } \\
\text { (Author-Year) }\end{array}$ & $\begin{array}{c}\text { Effect } \\
\text { Size }\end{array}$ & $\begin{array}{c}\text { Standard } \\
\text { Error }\end{array}$ & Variance & $\begin{array}{c}\text { Lower } \\
\text { Limit }\end{array}$ & $\begin{array}{c}\text { Upper } \\
\text { Limit }\end{array}$ & Z & $\mathrm{p}$ \\
\hline İdikut 2007 & 0.182 & 0.218 & 0.047 & -0.245 & 0.609 & 0.835 & 0.404 \\
Bayam 2012 & -0.058 & 0.303 & 0.092 & -0.652 & 0.536 & -0.192 & 0.848 \\
& 0.214 & 0.179 & 0.032 & -0.136 & 0.564 & 1.197 & 0.231
\end{tabular}




\begin{tabular}{cccccccc} 
& 0.083 & 0.177 & 0.031 & -0.264 & 0.430 & 0.469 & 0.639 \\
& -0.337 & 0.182 & 0.033 & -0.693 & 0.019 & -1.854 & 0.064 \\
Marshall 2000 & -0.040 & 0.177 & 0.031 & -0.386 & 0.307 & -0.225 & 0.822 \\
& 0.136 & 0.178 & 0.032 & -0.212 & 0.484 & 0.767 & 0.443 \\
& -0.043 & 0.177 & 0.031 & -0.390 & 0.303 & -0.245 & 0.807 \\
& 0.116 & 0.197 & 0.039 & -0.271 & 0.503 & 0.588 & 0.556 \\
Lim 2011 & 0.037 & 0.197 & 0.039 & -0.349 & 0.423 & 0.189 & 0.850 \\
& 0.219 & 0.198 & 0.039 & -0.169 & 0.606 & 1.107 & 0.268 \\
Bütüner 2014 & 0.438 & 0.199 & 0.040 & 0.047 & 0.829 & 2.195 & $0.028^{*}$ \\
Lit et all 2001 & 0.525 & 0.218 & 0.047 & 0.098 & 0.951 & 2.410 & $0.016^{*}$ \\
Overall & -0.067 & 0.229 & 0.053 & -0.516 & 0.383 & -0.290 & 0.772 \\
\hline
\end{tabular}

In accordance with Table 7, 14 standardized effect sizes, obtained from 6 studies, varies from -0.337 in favor of control group to 0.525 in favor of experimental group. A statistically significant difference ( $p$ $<0.05)$ was detected in only 2 effect sizes. The confidence interval was also found to vary from -0.693 and 0.951. Forest plot generated in CMA software regarding effect sizes of 6 studies is given below.

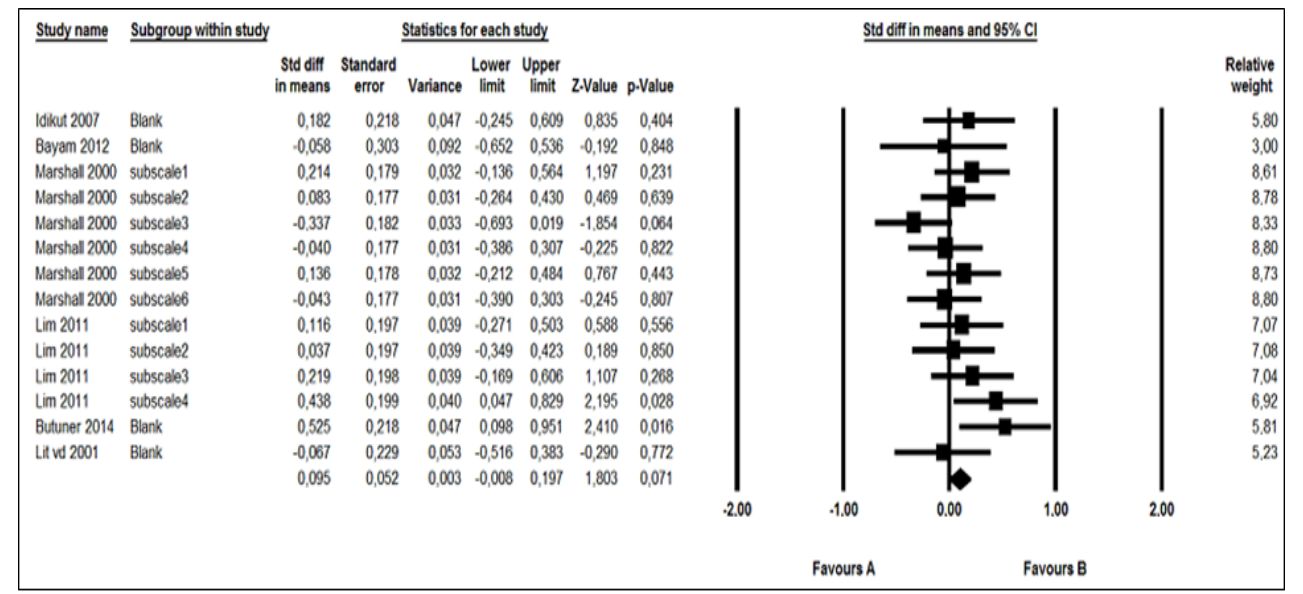

Figure 2.Forest plot about effect sizes of 6 studies

In Figure 2, the center of the shape indicates the average effect, and the width of the shape indicatesthe average confidence interval (Ried, 2006). While the largest confidence interval is Bayam (2012), the smallest one is Marshall (2000 subscale 1, 2, 3, 4, 5, 6).Figure 2 shows a difference higher than 0 in favor of experimental group. Average effect size is found 0.095. It is possible to make similar inference about mean effect size pursuant to forest plot. In line with calculations, we can talk about positive impact of using history mathematics on mathematics attitude of students. Average effect size is found 0.095 according to fixed effect model.

\section{Conclusions and Recommendations}

In this study, 14 effect sizes related to 6 studies constituting a sample of 364 people were calculated. Having found no publication bias using visual and statistical methods, the mean effect size was calculated. The heterogeneity tests ( $Q$ and $I 2$ statistics) revealed a low $(16 \%)$ level of heterogeneity, so fix effect model calculations were conducted. The mean effect size was found to be $d=0.095$ in favor of the group using HoM. According to Cohen et al. (2000), this effect size is low level, positive, and significant. Thalheimer and Cook (2002) mention that 0.095 is a negligible effect size. In the wake of meta-analysis, it is concluded that the students in experimental group, namely, using history of mathematics, have more positive attitude toward mathematics than those in control group who do not benefit from HoM but this positive change on experimental group is negligible. This consequence 
remains consistent in individual studies conducted in Turkey and abroad (Marshall, 2000; İdikut, 2007; Bayam, 2012). Tzanakis and Arcavi (2002) which state that history may pave way for confusion rather than clarifying mathematical concepts and that it is possible to consider history useless if we are to see the objective of mathematics lesson as solving routine problems. Therefore, usage of history mathematics may have smaller impact on students who prepare for central, nationwide exams, depending on how the implementers use history of mathematics during the process of learningteaching mathematics.

In literature, it is emphasized that using historical snippet can passivize students (Swetz, 1997; Fried, 2001) and alienate them from modern mathematics (Bütüner, 2014; Gönülateş, 2010). This fact has been proved by several research studies (McBride and Rollins, 1977; Dickey, 2001; Kaye, 2008; Tözluyurt, 2008). As a result of the study of Dickey (2001) it was ascertained that studens only liked Gelosia method of multiplication while they found the others as waste of time and irrelevant to modern mathematics. It was understood through the study of Tözluyurt (2008) that students found the method of Egyptians for multiplication rather difficult and preferred using modern methods. Although McBride and Rollins (1977) implied as an outcome of their study that using the history of mathematics increased students' attitudes, they also emphasized that an efficient use of the history of mathematics depends on targeted subject preference, way of usage andcharacteristics of samples. Consequently, the low/negligible effect size (E.S=0,095) might have been resulted from the contents of activities used within those studies, the way of using history of mathematics, knowledge/experience of the implementer and the structure of samples.

Details of previous studies should be easily accessible so that meta-analysis researches yield healthy results. Therefore, in Turkey, creation of electronic databases where it is possible to search various data sources such as theses, articles, and papers may ensure better conduct of meta-analysis researches. On the other hand, certain quantitative studies that concentrate on impact of history of mathematics on the mathematics attitude of students (Ho, 2008) are not included in hereby study since they lack necessary statistical values for calculation of effect size. Data analyses should abide by international standards in order to overcome such difficulties.

In hereby meta-analysis, the impact of using history of mathematics on mathematics attitude of students is examined, and other dependent variables are not excluded from content. Future researchers may conduct meta-analysis studies regarding impacts of using history of mathematics on the achievement, belief, and self-efficacy of students in mathematics.

\section{References}

The primary studies included in this meta-analysis are indicated by an asterisk $\left(^{*}\right)$.

Albayrak, Ö. (2011). Effects of history of mathematics integrated instruction on mathematics self-efficacy and achievement. Unpublished master dissertation, Boğaziçi University, İstanbul.

Aloe, A. M., Amo, L. C., \& Shanahan, M. E. (2014). Classroom management self-efficacy and burnout: a multivariate metaanalysis. Educational Psychlogical Review, 26, 101-126.doi: 10.1007/s10648-013-9244-0

Alpaslan,M., Isiksal, M.,\&Haser, C. (2014). Pre-service mathematics teachers' knowledge of history of mathematics and their attitudes and beliefs towards using history of mathematics in mathematics education. Science \& Education, 23(1), 159183.doi: 10.1007/s11191-013-9650-1

Aydın, A., Sarıer, Y., \& Uysal, Ş. (2011). The Effect of gender on organizational commitment of teachers: a meta analytic analysis. Educational Sciences: Theory \& Practice, 11(2), 615-633.

Aydoğdu, N.,\& Yüksel, İ. (2013). The relationship between prospective mathematics teachers' beliefs and attitudes towards history of mathematics and their creativeness level. Journal of Research in Education and Teaching, 2(4), 186-194.

Awosanya, A. (2001). Using history in the teaching mathematics. Unpublished doctoral dissertation, Florida State University, America.

Arcavi, A. (1991). Two benefits of using history. For the learning of mathematics, 11(2), 11.

Baki, A. (2008). Kuramdan uygulamaya matematik eğitimi. Trabzon: Harf Eğitim Yayıncılığı. 
Baki, A.,\& Güven, B. (2009). Khayyam with Cabri: experiences of pre-service mathematics teachers with Khayyam's solution of cubic equations in dynamic geometry environment. Teaching mathematics and Its Applications, 28, 1-9. doi: 10.1093/teamat/hrp001

Baki, A.,\& Bütüner, S. Ö. (2013). The ways of using the history of mathematics in 6th, 7th and 8th grade mathematics textbooks. Elementary Education Online, 12(3), 849-872, 2013.

Banks, G. C., Kepes, S., \& Banks, K. P. (2012). Publication bias: The antagonist of meta-analytic reviews and effective policymaking. Educational Evaluation and PolicyAnalysis, 34(3), 259-277.

Barwell, M. (1913). The advisability of including some instruction in the school course on history of mathematics. The Mathematical Gazette, 7, 72-79.

Başıüyük, K. (2012). The use of mathematics history in mathematics courses: İbrahim Hakk perspective and Babylonian method sample. Unpublished master thesis, Atatürk University, Erzurum.

*Bayam, S. B. (2012). The impact of a knowledge of the history of mathematics on primary school student mathematics achievement and attitudes. Unpublished master thesis, Kastamonu University, Kastamonu.

Bellomo, C.,\& Wertheimer, C. (2010). A discussion and experiment on incorporating history into the mathematics classroom. Journal of College Teaching \& Learning, 7(4), 19-24.

Bidwell, J. (1993). Humanize your classroom with the history of mathematics. The Mathematics Teacher, 86(6), 461-464.

Borenstein, M., Hedges, L. V., Higgins, J. P. T., \& Rothstein, H. R. (2009). Introduction to meta-Analysis. West Sussex-UK: John Wiley \& Sons Ltd.

Borenstein, M., Hedges, L., Higgins, J., \& Rothstein, H. (2005). Comprehensive meta- analysis version 2. Englewood, NJ: Biostat.

Burns, B. A. (2010). Pre-service teachers' exposure to using the history of mathematics to enhance their teaching of high school mathematics. Issues in the Undergraduate Mathematics Preparation of School Teachers: The Journal, 4, 1-9.

*Bütüner, S. Ö. (2014). Reflections from classroom environments enriched with the mathematics historical activities: an action research. Unpublished doctoral dissertation, Karadeniz Technical University, Trabzon.

Camnalbur, M.,\& Erdoğan, Y. (2008). A meta analysis on the effectiveness of computer-assisted instruction: Turkey Sample. Educational Sciences: Theory and Practice, 8, 497-505.

Card, N. A. (2012). Applied meta-analysis for social science research. New York: The Guilford Press.

Charalambous, C. Y., Panaoura, A., \& Philippou, G. (2009). Using the history of mathematics to induce changes in preservice teachers' beliefs and attitudes: insights from evaluating a teacher education program. Educational Studies in Mathematics, 71(2), 161-180.doi: 10.1007/s10649-008-9170-0

Clark, K. M. (2012). History of mathematics: illuminating understanding of school mathematics concepts for prospective mathematics teachers. Educational Studies in Mathematics, 81(1), 67-84.doi: 10.1007/s10649-011-9361-y

Cohen, J. (1988). Statistical power analysis for the behavioral sciences.Academic Pres., New York.

Cohen, J., Welkowitz, J., \& Ewen, R. B. (2000). Introductory statistics for the behavioral science.Harcourt Brace College Publishers, Orlando.

Cooper, H. M. (1989). Integrating research: A guide for literature reviews. Newbury Park, CA: Sage.

Cooper, H., Hedges, L. V., \& Valentine, J. C. (eds.). (2009). The Handbook of Research Synthesis and Meta Analysis (2nd edition). New York: Russell Sage Publication.

Darabi, A., Liang, X., Suryavanshi, R., \& Yürekli, H. (2013). Effectiveness of online discussion strategies: a meta analysis. American Journal of Distance Education, 27, 228-241. doi: 10.1080/08923647.2013.837651

Dickey, G. (2001). A historical approach to teaching the british columbia mathematics eight course. Unpublished master dissertation, Simon Fraser University.

Ellis, P. D. (2012). The essential guide to effect sizes (5th edition). Cambridge-UK: Cambridge University Press.

Ernest, P. (1998). The history of mathematics in the classroom. Mathematics in School, 27(4). 25-31.

Fauvel, J. (1991). Using history in mathematics education. For the Learning of Mathematics, 11(2), 3-6.

Fenaroli, G., Furinghetti, F., \& Somaglia, A. (2014). Rethinking mathematical concepts with lens of the history of mathematics: an experiment with prospective secondary teachers. Science \& Education, 23(1), 185-203. doi: 10.1007/s11191-013-9651-0

Fried, N. M. (2001). Can mathematics education and history of mathematics coexist?.Scince and Education, 10,391-408. doi: 10.1023/A:1011205014608

Furinghetti, F. (2007). Teacher education through the history of mathematics. Educational Studies in Mathematics, 66(1), $131-143$. doi: 10.1007/s10649-006-9070-0

Gazit, A. (2013). What do mathematics teachers and teacher trainees know about the history of mathematics?.International Journal of Mathematical Education in Science and Technology, 44(4), 501-512. doi: 10.1080/0020739X.2012.742151

Glaubitz, M. R. (2007). The use of original sources in the classroom. Proceedings of the 5th European Summer University, Prague, July 19-24.

Goodwin, D. M. (2007). Exploring the relationship between high school teachers' mathematics history knowledge and their images of mathematics. Unpublished doctoral dissertation, University of Massachusetts Lowell.

Gönülateş, F. O. (2004). Prospective teachers' views on the integration of history of mathematics in mathematics courses. Unpublished master dissertation, Boğaziçi University, İstanbul.

Grootenboer, P \& Hemmings, B (2007). Mathematics performance and the role played byaffective and background factors. Mathematics Education Research Journal, 19(3), 3-34.

Groza, S. V. (1968). A survey of mathematics: elementary concepts and their historical development, USA: Holt Rinehart and Winston.

Gulikers, I.,\& Blom, K. (2001). A historical angle, a survey of recent literature on the use and value of history in geometrical education. Educational Studies in Mathematics, 47, 223-258. doi: 10.1023/A:1014539212782 
Gürsoy, K. (2010). A survey of prospective mathematics teachers' beliefs and attitudes towards using the history of mathematics in mathematics teaching. Unpublished master thesis, Karadeniz Technical University. Trabzon.

Haile, T. K. (2008). A Study on the use of history in middle school mathematics: The Case of Connected Mathematics Curriculum. Unpublished doctoral dissertation, The University of Texas at Austin.

Haverhals, N.,\& Roscoe, M. (2010). The history of mathematics as a pedagogical tool: teaching the integral of the secant via Mercator's projection. The Montana MathematicsEnthusiast, 7(2-3), 339-360.

Higgins, J. P. T., Thompson, S. G., Deeks, J. J., \& Altman, D. G. (2003). Measuring inconsistency in meta-analyses. Retrieved from http://eprints.lincoln.ac.uk/1932/1/MetaAnalysisPaper.pdf

Ho, W. K. (2008). Using history of mathematics in the teaching and learning of mathematics in Singapore. Paper presented at the 1st RICE, Singapore: Raffles Junior College.

Horton, L. B. (2011). High school teachers' perception of the inclusion of history of mathematics in the classroom. Unpublished doctoral dissertation, University of Massachusetts lowel.

Hunter, J. E.,\& Schmidt, F. L. (2004). Methods of Meta-analysis: Correcting Error and Bias in Research Findings (3rd ed.). Thousand Oaks, CA: Sage.

Huntley, M. A. \& Flores, A. (2010). A history of mathematics course to develop prospective secondary mathematics teachers' knowledge for teaching. Primus, 20(7), 603-616. doi: 10.1080/10511970902800494

*idikut, N. (2007). The effect of benefiting from history in education of mathematics on the student's attitudes towards mathematics and their success on it. Unpublished master thesis, Yüzüncü Yıl University, Van.

Jankvist, T. U. (2009a). Using history as a goal in mathematics education. Unpublished doctoral dissertation, Roskilde University.

Jankvist, T. U. (2009b). A categorization of the whys and hows of using history in mathematics education. Educational Studies in Mathematics Education, 71(3), 235-261. doi: 10.1007/s10649-008-9174-9

Jankvist, T. U. (2010). An emprical study of using history as a 'goal'. Educational Studies in Mathematics Education, 74(1), 5374.doi:10.1007/s10649-009-9227-8

Karaduman, G. B. (2010). A sample study for classroom teachers addressing the importance of utilizing history of math in math education. Procedia - Social and Behavioral Sciences, 2(2), 2689-2693. doi: 10.1016/j.sbspro.2010.03.397

Kaye, E. (2008). The aims of and responses to a history of mathematics videoconferencing project for schools, Proceedings of the British for Research into learning mathematics 28(3).http://bsrlm.org.uk/IPs/ip28-3/BSRLM-IP-28-3-12.pdf

Kaygın, B., Balçın, B., Yıldız, C., \& Arslan, S. (2011). The effect of teaching the subject of fibonacci numbers and golden ratio through the history of mathematics. Procedia Social and Behavioral Sciences, 15, 961-965.doi: 10.1016/j.sbspro.2011.03.221

Kış, A. (2013). The views of administrators and teachers on levels of principals instructional leadership behaviours: A meta-analysis. Unpublished doctoral dissertation, İnönü University, Malatya.

Krussel, L. (2000). Using history to further the understanding of mathematical concepts. Primus, 10(3), 273-276. doi: 10.1080/10511970008965966

Lawrence, S. (2006). Maths is good fot you: web-based history of mathematics resources for young mathematicians and their teachers. Journal of the British Society for the History of Mathematics, 21, 90-96. doi: 10.1080/17498430600803375

Leng, N. W. (2006). Effects of an ancient chinese mathematics enrichment programme on secondary school students' achievement in mathematics. International Journal of Science and Mathematics Education, 4, 485-511. doi: 10.1007/s10763005-9017-4

*Lim, S. Y. (2011). Effects of using history of mathematics on junior college students' attitudes and achievement, AAMTMERGA Conference 2011 Mathematics: Traditions and New Practices, 3-7 July.

Lipsey, M. W.,\& Wilson, D. B. (2001). Practical Meta-Analysis. Thousand Oaks, CA: SAGE Publications, Inc.

${ }^{*}$ Lit, C. K., Siu, M. K., \& Wong, N. Y. (2001). The use of history in the teaching of mathematics: theory, practice, and evaluation of effectiveness. Educational Journal, 29(1), 17-31.

Liu, P. (2003). Do teachers' need to incorporate the history of mathematics in their teaching?.Mathematics Teacher, 96(6), 416-421.

Liu, P.,\& Niess, M. L. (2006). An exploratory study of college students' views of mathematical thinking in a historical approach calculus course. Mathematical Thinking and Learning, 8(4), 373-406. doi:10.1207/s15327833mt10804_2

Liu, P. H. (2009). History as a platform for developing college students' epistemological beliefs on mathematics. International Journal of Science and Mathematics Education, 7(3), 473-499. doi: 10.1007/s10763-008-9127-x

*Marshall, G. L. (2000). Using history of mathematics to improve secondary students' attitudes toward mathematics. Unpublished doctoral dissertation, Illinois State University.

Mayfield, B. (2001). A history of mathematics course as a senior seminar. Primus, 11(3), 245-257.

McBride, C. C.,\& Rollins, H. J. (1977). The effects of history of mathematics on attitudes toward mathematics of college algebra students. Journal for Research in Mathematics Education, 8(1), 57-61.

Miller, C. C. (2002). Teaching the history of mathematics. Primus, 12(4), 334-346.

Nataraj, M. S.,\& Thomas, M. O. J. (2009). Developing understanding of number system structure from the history of mathematics. Mathematics Education Research Journal, 21(2), 96-115. doi:10.1007/BF03217547

Özcan, Ş. (2008). The effect of gender of education administrators and of education administrators who participated in the service training to their tasks: a meta-analysis. Unpublished doctoral dissertation, Marmara University, İstanbul.

Özcan, Ş.,\& Bakioğlu, A. (2010). A meta-analytic effect analysis: the effect of in-service training on the job performance of school administrators. Hacettepe University Journal of Education, 38, 201-212.

Özdemir, A. Ş., Göktepe, S., \& Kepçeoğlu, İ. (2012). Using mathematics history to strengthen geometric proof skills. Procedia Social and Behavioral Sciences, 46, 1177-1181.doi: 10.1016/j.sbspro.2012.05.270

Panasuk, R. M.,\& Horton, L. B. (2012). Integrating history of mathematics into curriculum: what are the chances and constraints?.InternationalElectronic Journal of Mathematics Education, 7(1), 3-20. 
Percival, I. (1999). Mathematics in history: integrating the mathematics of ancient civilizations with the grade 7 social studies curriculum. Unpublished master dissertation, Simon Fraser University.

Percival, I. (2004). The use of cultureş perspectives in the elementary school mathematics classroom. Unpublished doctoral dissertation, Simon Fraser University.

Petticrew, M.,\& Roberts, H. (2006). Systematic Reviews in the Social Sciences. MAUSA: Blackwell Publishers Ltd.

Petitti, D. B. (2000). Meta-Analysis, Decision Analysis, and Cost-Effectiveness Analysis (2nd edition). New York: Oxford University Press.

Pincus, T. C., Miles, C., Froud, R., Underwood, M., Carnes, D., \& Taylor, S. J. C. (2011). Methodological criteria for the assessment of moderators in systematic reviews of randomised controlled trials: A consensus study. BMC Medical ResearchMethodology 11: 14. doi:10.1186/1471-2288-11-14

Ponza, M. V. (1998). A role for the history of mathematics in the teaching and learning of mathematics: An Argentinean experience. Mathematics in School, 27(4), 10-13.

Povey, H. (2014). Walking in a foreign and unknown landscape: studying the history of mathematics in initial teacher education. ScienceEEducation, 23(1), 143-157.doi: 10.1007/s11191-013-9617-2

Preston, J. A. (2007). Student centered versus teacher centered mathematics instruction: a meta-analysis. Unpublished doctoral dissertation, Indiana University of Pennsylvania.

Rachel, B. (2007). A meta-analysis of the relationship between extraversion and academic achievement. Unpublished doctoral dissertation, Hofstra University.

Ried, K. (2006). Interpreting and understanding metaanalysis graphs. Australian Family Physician, 35(8), 635-638.

Rosenthal, D., Hoyt, W., Ferrin, J., Miller, S., \& Cohen, N. (2006). Advanced methods in meta-analytic research: Applications and implications for rehabilitation counseling research, Rehabilitation Counseling Bulletin, 49(4), 234246.doi: 10.1177/00343552060490040501

Rothstein, H. R., Sutton, A. J., \& Borenstein, M. (2005). Publication bias in meta-analysis. In H. R. Rothstein, A. J. Sutton \& M. Borenstein (Eds.), Publication bias in meta-analysis: Prevention, assessment and adjustments. West Sussex, England: John Wiley \& Sons.

Shelby, L. B.,\& Vaske, J. J. (2008). Understanding metaanalysis: A review of the methodological literature. Leisure Sciences:An Interdisciplinary Journal, 30 (2), 96-110. doi:10.1080/01490400701881366

Siu, M. K. (2007). No, I don't use history of mathematics in my class. why? In F. Furinghetti, S. Kaijser, and C. Tzanakis (Eds.), Proceedings HPM2004 \& ESU4(revised edition, pp. 268-277). Uppsala: Uppsala Universitet.

Smestad, B. (2008). Teachers' conceptions of history of mathematics. Retrieved on 12- March-2012, at URL: http://home.hio.no/ bjorsme/HPM2008paper.pdf.

Sullivan, K. M. (2000). Preservice secondary mathematics teachers' attitudes about the history of mathematics. Unpublished master thesis, University of Nevada, Las Vegas.

Swetz, J.W.(1997). Using problems from the history of mathematics in classroom instruction, İçinde, (Ed: Swetz, F., Fauval, J., Bekken, O., Johansson, B.,\& Katz, V.). Learn from the masters, The Mathematical Association of America.

Şen, Ş.,\& Yılmaz, A. (2013). The effect of cooperative learning on conceptual change: a meta-analysis study..Karaelmas Journal of Educational Sciences, 1(1), 21-32.

Thalheimer, W.,\& Cook, S. (2002). How to calculate effect sizes from published research articles: A simplified methodology. http://worklearning.com/effect_sizes.htm erişim tarihi: 20 Temmuz 2013

Tavil, Y. Z.,\& Karasu, N. (2013). Parent training studies: a review and meta-analysis. Education and Science, 38(168), 85-95.

Tokpah, C. L. (2008). The effects of computer algebra systems on students' achievement in mathematics. Unpublished doctoral dissertation, Kent State University College and Graduate School of Education.

Tözluyurt, E. (2008). The perceptions of senior high students regarding the lessons, in which activities chosen from history of mathematics are used on the subject of numbers learning area. Unpublished master thesis, Gazi University, Ankara.

Tzanakis, C.,\& Arcavi, A. (2002). Integrating history of mathematics in the classroom: an analytic survey, In Favuel, J. and Van Manen, J. (Eds.), History in mathematics education(pp. 201-240), Netherlands: Kluwer Academic Publishers.

Üstün, U. (2012). To what extent is problem based learning effective as compared to traditional teaching in science education: a metaanalysis study. Unpublished doctoral dissertation, Middle East Technical University, Ankara.

Ustün, U.,\& Eryılmaz, A. (2014). A Research Methodology to Conduct Effective Research Syntheses: Meta-Analysis. Education and Science, 39(174), 1-32. doi: 10.15390/EB.2014.3379

Viera, A. J.,\& Garrett, J. M. (2005). Understanding interobserver agreement: The Kappa statistic. Family Medicine, 37(5), 360-363.

Wilson, P. S.,\& Chauvot, J. B. (2000). Who? How? What? A strategy for using history to teach mathematics. Mathematics Teacher, 93(8), 642-645.

Yenilmez, K. (2011)..Prospective mathematics teachers' opinions about the history of mathematics course. Pamukkale University Journal of Education, 30, 79-90.

Yevdokimov, O. (2007) Using the history of mathematics for mentoring gifted students: Notes for teachers. In: The 21st Biennial Conference of the Australian Association of Mathematics Teachers Inc., 6-9 July 2007, Hobart, Australia.

Yıldiz, N. (2002). Meta analysis method in data evaluation. Unpublished master thesis, Marmara University, İstanbul.

Yildiz, C. (2013). Analysis of history of mathematics usage of secondary school mathematics teachers on their lessons: Reflections on inservice training. Unpublished doctoral dissertation, Karadeniz Technical University, Trabzon. 